\title{
O USO DO FILME NA FORMAÇÃO DE PROFESSORES
}

\section{Adriana Varani \\ Laura Noemi Chaluh}

\section{RESUMO}

Em nossas práticas educativas como professoras na formação inicial e continuada de professores e em nossos processos formativos, temos usado os filmes em sala de aula. Estas experiências nos levaram a refletir sobre a importância dos seus usos na formação de professores. As produções de Napolitano, Miranda, Almeida, Oliveira Jr., dentre outros, nos permitiram problematizar acerca do seu uso na escola. Trazemos para a discussão uma experiência de aula e a partir dela discutimos o uso do filme no trabalho pedagógico. Afirmamos a necessidade de valorizar o filme como um produto cultural na sala de aula, quando a partir da experiência referida foi possível explicitar as múltiplas leituras que o filme provoca. Resgatamos neste artigo a idéia da experiência estética e suas implicações no contexto da sala de aula e discutimos acerca da intencionalidade do uso do filme nesse mesmo contexto.

\section{PALAVRAS-CHAVE}

Formação de professores; Filmes; Práticas pedagógicas

\section{USE OF FILMS IN TEACHER EDUCATION}

\begin{abstract}
In our educational practices as professors of the initial and continued formation of teachers and in our formative processes, we have used the video-recording of lessons. These experiences led us to reflect on the importance of their uses in teacher formation. The productions of Napolitano, Miranda, Almeida, Oliveira Jr., among others, allowed us to problematize about their use in school. We bring to the discussion a classroom experience and from this experience we discuss the use of video in the pedagogic work. We affirm the necessity to value the video as a cultural product of the class, since from the above-mentioned experience it was possible to state explicitly the multiple readings that the video provokes. We rescue in this article the idea of aesthetic experience and its implications in the context of the class and we discuss about the intentionality of the use of video in that same context.
\end{abstract}

\section{KEYWORDS}

Teacher education; Video; Pedagogical practice 


\section{DESVELANDO AS NOSSAS INQUIETAÇÕES}

Somos professoras de professores, tanto nos cursos de formação inicial, como em cursos de formação continuada. Em ambos os casos, nós temos possibilitado em nossas aulas, o encontro com diferentes filmes.

Nas nossas conversas, ao lembrar dos nossos próprios processos de formação, temos resgatado alguns episódios que foram marcantes para ambas: a experiência de ter assistido a filmes nas aulas quando estudantes. Esses momentos apareceram como muito significativos, tanto que temos oportunizado em nosso trabalho a possibilidade de compartilhar a "leitura de filmes" com nossos alunos.

Nesse sentido, neste artigo abordaremos questões relativas aos usos dos filmes na formação de professores e para isso apresentamos uma experiência concreta, os registros escritos de uma aluna após ter assistido um filme. Ao socializar esse episódio, trazemos para a discussão as múltiplas leituras que um sujeito consegue produzir após a experiência estética e que, neste artigo, pretendemos discutir pensando na leitura didática e na leitura estética.

Pensarmos uma obra como um objeto que possibilita várias leituras dos conteúdos trabalhados pela escola é pensar um posicionamento da didática. Este posicionamento parte de uma didática fundamental ${ }^{1}$ (CANDAU, 1985) que nega uma didática meramente instrumental, mas que considera o contexto, as relações estabelecidas e a não neutralidade do processo de “ensinagem” e aprendizagem. Tal posicionamento não se fundamenta numa visão do conteúdo como único, verdadeiro e independente de qualquer posicionamento de poder, mas que no contexto da escola este conteúdo está carregado de ideologia e, portanto no seu trato metodológico, diversas interpretações são mobilizadas.

Para concretizar nossa intencionalidade de reflexão, nos parece necessário dizer dos lugares desde onde falaremos. São dois os lugares marcados: o lugar e o olhar a partir das nossas experiências como alunas; o lugar e o olhar a partir das nossas experiências como professoras.

\footnotetext{
${ }^{1}$ Vera Candau em seu livro “A Didática em Questão”, inaugura a perspectiva crítica da didática no Brasil denominada didática fundamental. Este movimento, pela redefinição da didática, é reação a um tipo de didática baseada na neutralidade, fundada na idéia de didática como método único de ensino e conseqüentemente nos seus procedimentos formalizados
} 
Como professoras, temos ressignificando nossas experiências como alunas, e apoiando-nos no repertório/conhecimento apreendido, temos utilizado filmes na nossa atuação na formação inicial e continuada de professores. Nesse sentido, temos um interesse especial por refletir sobre a potencialidade dos filmes na formação de professores.

\section{FORMAÇÃO DE PROFESSORES}

Ao tomarmos a iniciativa da escrita sobre o uso dos filmes, optamos por pensá-lo na formação de professores em razão de nossas experiências formativas e formadoras (que também formativas!).

E por que nos mobiliza pensar a nossa formação e nossa ação como formadoras? Dentre outros motivos, tendemos a pensar que a formação de professores durante os últimos tempos tem se alterado substancialmente. De perspectivas que privilegiam os manuais didáticos nos processo formativos, a perspectiva que enfatizam os meios, técnicas de ensino tecnicismo - os cursos passaram a pensar na sólida formação teórica e mais recentemente, acompanhada desta perspectiva, uma tendência a olhar para o cotidiano da escola, para as práticas pedagógicas e, a partir de sua complexidade, formar-se por ela ${ }^{2}$.

E sobre a questão do cotidiano, Alves (2002), autora interessada pela pesquisa no/do cotidiano da escola, aponta: “admito, ainda, que como a vida, o cotidiano é um 'objeto' complexo, o que exige também métodos complexos para conhecê-lo” (p. 15). Quais as nossas estratégias na sala de aula para possibilitar que futuros professores tenham elementos para conhecer esse cotidiano complexo?

Não é a toa que muitos dos estudos sobre esta temática, privilegiam a forte presença de reflexões sobre prática pedagógica a fim de nos mobilizarmos e passar de um “discurso comprometido” para um “fazer comprometido” com uma educação emancipatória 3 .

\footnotetext{
${ }^{2}$ Hargreaves (1998) aponta a impotência do discurso da formação docente em relação com o que os futuros docentes pensam, fazem e acabam fazendo na escola: "lo que moldea a los docentes cuando aprenden a enseñar son las culturas, estructuras y constreñimientos del sistema escolar existente, más allá de las instituciones de formación docente” (p. 136). Estamos defendendo que estas culturas e estruturas que são próprias da escola, sejam problematizadas no âmbito da Universidade na formação inicial.

${ }_{3}^{3}$ Resgatamos as considerações de Dickel, (2000) quando reflete acerca de nós professoras "que ao optar pela luta (que é fundamentalmente) coletiva por alternativas viáveis e comprometidas com a especificidade e o valor
} 
Mas o que esta perspectiva de ler/enxergar/olhar o cotidiano nos ensinou? Ensinou-nos a complexidade de fazeres, a complexidade de relações, de idéias, de posturas possíveis nele. Ensinou-nos que não há linearidade, que não há só um caminho, uma forma, uma estratégia para ensinar e para aprender, que não há só uma forma de pensar, e que podemos nos relacionar com os conhecimentos de outras formas das estipuladas pela ciência moderna. Que a escola pode ser pensada com outra configuração, outros tempos e outros espaços.

E como lidar com esta diversidade se, nos processos formativos, tentamos “controlar” os sentidos dos sujeitos, através de leituras de manuais didáticos, que pode nos confortar como professores numa aparente segurança, mas não possibilitam a compreensão dos diversos sentidos que o trabalho pedagógico pode suscitar? Como fugir dos planejamentos de atividades onde a implicação dos alunos é desconsiderada, assim como também é desconsiderada a cultura e experiências dos nossos alunos? Acreditamos que uma estratégia importante para quebrar a nossa própria imagem da escola, a escola que temos “vivido” quando alunas, seja apresentando outras linguagens na sala de aula nos processos formativos.

Garcia e Alves (2002) questionam, a formação oferecida nas universidades, à medida que a questão cultural, para elas é tratada como menor. Nesse sentido apontam que nas salas de aulas, dificilmente se fazem propostas de fazer redes com os conhecimentos desenvolvidos em diferentes áreas de conhecimento e diferentes áreas artísticas. Assim, segundo as autoras, os próprios formadores ao não ter acesso a teatros, cinemas, enfim vida cultural, também não sabem como fazer com que seus alunas e alunos tenham. Assim, elas apontam a importância de tecer múltiplas redes de contatos, junto com a necessidade de oferecer atividades que guardem relação com a questão cultural.

\footnotetext{
"Não se trata de formar o pesquisador, somente, mas de reconhecer no sujeito da prática essa capacidade de interrogar a realidade em que vive, tanto quanto sua própria prática, colocando-a em contato, sempre, com o mundo todo, interrogandoo, no mesmo movimento” (2002, p. 110).
}

do trabalho docente e com uma educação que fomente nas crianças a potencialidade de inventar e lançar as bases de um mundo diferente” (p. 41). 
Garcia e Alves (2002) oferecem-nos respostas às inquietações explicitadas por nós neste artigo. Romper/quebrar com a linearidade de pensamento, romper com a idéia de uma escola “ideal”, abandonar a idéia de que na escola não devam existir conflitos, ou seja, começar a dar visibilidade à positividade da escola, resgatando o que nela existe, no que nela acontece (ROCKWELL; EZPELETA, 1986). Implica também começar a pensar e a refletir sobre nós.

Uma discussão importante é apontada por Garcia e Alves (2002), elas referem-se as diferentes linguagens presentes na nossa cultura que podem nos conduzir a possíveis respostas frente às tantas interrogações (ou inquietações) que surgem quando pensamos nos acontecimentos que se sucedem na escola no cotidiano. Nesse sentido, ao ocupar o lugar de professoras nas escolas, é preciso nos interrogar, nos inquietarmos, perguntarmos, questionarmos não só sobre a realidade, mas também sobre nossas práticas. Em definitivo, questionarmos sobre a nossa própria realidade.

A formação de professores esteve imbricada, durante muito tempo, especialmente no tempo da escola para poucos, num fazer supostamente igual dentro do mundo educacional. Ao passarmos pela política da expansão do atendimento e da entrada na escola das classes populares, antes nem ingressantes dela, podemos concluir que houve seu sucateamento, não pela culpa motivada pelos que entraram, mas pela composição do currículo, pela organização do trabalho pedagógico que não privilegiou este novo aluno. Como aponta Gimeno Sacristán (1997) a escola tem se configurado tanto na sua ideologia como nos seus usos organizativos e pedagógicos como um instrumento de homogeneização dentro da cultura dominante. Assim, a escola não consegue acolher e dar expressão às "singularidades". Essas dificuldades guardam relação com os processos de taylorização e homogeneização dos tratamentos pedagógicos.

A formação de professores, neste contexto, foi tendo que se questionar. E hoje, há um grande gama de propostas que tentam produzir outros olhares para a prática pedagógica, vendo-a tanto como reprodutora do conhecimento socialmente válido, como produtora de novos conhecimentos.

No campo da metodologia dos cursos de formação, podemos elencar, dentre outras, duas iniciativas para esta mudança. 
Por um lado, a iniciativa da consideração do professor pesquisador, professor que também se posiciona e produz, assume o seu lugar e reconhece a importância do seu trabalho e do que a partir dele é produzido no seu cotidiano: saberes e conhecimentos (GERALDI, 2004; DAMASCENO, 2005, GERALDI, 1993), seja pela pesquisa (GERALDI, 1993) seja pela presença da reflexão pelo trabalho (FREITAS, 1993). Na mesma linha também consideramos as idéias de Kramer (1997) que defende a autoria do trabalho do/pelos professores, especialmente ao questionar como eles podem se tornar construtores de conhecimentos quando são reduzidos a executores de propostas e projetos de cuja elaboração não participaram e que são chamados apenas a implantar.

Por outro lado, o aparecimento do uso de outras linguagens, nos cursos de formação de professores, dentre eles o filme (NAPOLITANO, 2003; BOLOGNINI, 2007), a literatura (CHALUH, 2005), é resultado também da percepção da dimensão multilateral da formação humana - dimensão cultural e estética. Assim nasce a necessidade de prever diferentes formas de expressão para a leitura do mundo.

É neste aspecto que gostaríamos de nos fixar, na valorização de outras linguagens no trato teórico-metodológico da formação de professores. Algumas pistas podem nos ajudar a encontrar sentidos acerca desse aparecimento. Talvez, esteja diretamente relacionada com a evidência da necessidade que todos nós, professores, temos de ter respostas outras às dificuldades que se apresentam no cotidiano e que não condizem com essas respostas gerais, estatísticas, unívocas (CERTEAU, 2002). Parece-nos que outras linguagens nos oferecem mais possibilidades para poder ter uma compreensão da escola que temos e conhecemos, e não da escola ideal da qual tanto se fala. Isto não significa que não temos um ideal de escola, mas o que nos parece é que nas produções teóricas há uma idealização da escola, quando é apresentada de forma uniforme e desconsiderando a sua singularidade. A escola, muitas vezes, aparece como espaço onde não ocorrem conflitos/embates, na qual não há vida carregada de diferentes posicionamentos, na qual não existem relações de poder, enfim um espaço lido como se não fosse complexo. A medida que a linguagem da literatura e do filme se aproxima da existência dos conflito. A leitura proporcionada a partir deles pode nos conduzir a pensar o mundo desde outras perspectivas.

Dentre essas linguagens, focamos neste trabalho os filmes, considerando que eles são uma narrativa. Como nos lembra Oliveira Jr. (1999), “todo filme é uma narrativa, e como 
tal conta uma história por meio da projeção de imagens e sons específicos, únicos, uma vez que foram captados na realidade, onde cada coisa (objetos, pessoas, animais, etc) é única entre todas”“4 (p. 179).

Ainda com a idéia de narrativa, o mesmo autor, aponta que as pinturas e os filmes não têm como objetivo contar algo como realmente ocorreu ou como realmente é; as pinturas e os filmes “querem apresentar uma experiência humana” (OLIVEIRA JR., 1999, p. 170).

Neste sentido há uma tendência atual de resgate de produções do gênero narrativo como forma de recuperar as nossas experiências, nossas histórias, fazendo não só uma possível leitura de nosso próprio mundo, como também do mundo. E esse resgate é valorizado atualmente no mundo educacional, no trato teórico-metodológico na formação docente. No caso do curso de formação de professores, as narrativas dos filmes podem proporcionar aos alunos uma experiência estética a partir da qual conseguem produzir leituras do mundo.

O filme é representativo de uma narrativa que está presente nos processos educativos em seus diversos níveis, assim como está a literatura, a recuperação da memória. O estudo a partir de narrativas diversas possibilita olhar para um acontecimento, ou para um fenômeno a partir de outros elementos que não aqueles ditados por manuais didáticos. Neste sentido utilizar estas linguagens é complementar ao trabalho da escola de transmissão e perpetuação de uma herança cultural.

O filme na sala de aula pode possibilitar o heterogêneo, fazendo emergir múltiplas leituras, e possibilita uma crítica à formação de professores dentro de um contexto de uma escola "ideal”.

Por que tanta inquietação de nossa parte sobre a formação das professoras e o uso de diferentes linguagens na sala de aula? Até aqui alguns teóricos nos ofereceram algumas pistas para isso: romper com as “formas”, "sair do estabelecido”. Quem sabe as múltiplas linguagens nos permitam olhar para nós mesmos não mais como simples executores/técnicos e podemos nos dirigir para a busca de pensar em nós e nos “inéditos viáveis”, de Paulo Freire. Assim, pensar em possibilidades outras, nos leva a pensar em outras relações tanto na sala de aula como na escola, e para isso acreditamos que seria importante pensar em um professor

\footnotetext{
${ }^{4}$ Mesmo quando não há a intenção de ser narrativa, as nossas tradições cinematográficas e nosso olhar como espectador nos conduz a fazer a leitura de uma narrativa.
} 
que tenha a possibilidade de abrir seu sentir e seu pensar por outros caminhos que não os já estabelecidos.

\title{
DAS SENSAÇÕES PROVOCADAS PELOS FILMES NA FORMAÇÃO DE PROFESSORES
}

Para provocar a problematização das dimensões do uso de filmes na aula partimos para a compreensão dos efeitos que mobilizam essas produções nos indivíduos. Para Miranda (1998):

\begin{abstract}
"O estudo das imagens nos leva a pensar a articulação de saberes, conhecimentos, percepções, emoções e memória que a 'psique' (alma) humana movimenta quando olha para elas. Em vista disso, a aprendizagem, enquanto tema educacional, tornase mais complexa - histórica e cognoscível. Esta experiência permite a emersão de dimensões humanas geralmente esquecidas pelas teorias da aprendizagem: o inconsciente, a imaginação, os mitos, os arquétipos, os deuses, o sagrado” (p.15).
\end{abstract}

É pela verdade da emersão de diversas dimensões humanas quando do olhar para o filme que gostaríamos de nos remeter às emoções primeiras.

Ao ser solicitado que os alunos de uma disciplina do curso de pós-graduação, assistissem ao filme "A Maçã” ${ }^{5}$, Lana ${ }^{6}$ fez o exercício e repleta dos sentidos mobilizados nela a partir da sua leitura, construiu o seguinte relato.

\begin{abstract}
Minhas impressões ${ }^{7}$
Escuto os primeiros sons. O cenário, as vestimentas. Achei que estava em um lugar conhecido por mim. Esse idioma me era familiar... E foram aparecendo os meus avós, os quatro nascidos em Síria. Minhas lembranças de criança quando eu escutava falar a eles em uma outra língua, quando eu os escutava cantar outras músicas, outros movimentos e outras danças. Apareceram também os sabores e cheiros da cozinha ..., outras comidas. Outra cultura. Sim é outra cultura.

Para mim foi muito marcante um aspecto que foi tratado no filme, o fato de ser MULHER dentro de essa cultura. O antigo mandato de ter que se casar. Como fala no filme: Deus fez a mulher para se casar! E então prepara as filhas para isso. A desvalorização de ser mulher nessas sociedades. [...] E lembro do PODER DA PALAVRA.
\end{abstract}

A porta fechada. Olhar para essas meninas que não podiam caminhar corretamente,

\footnotetext{
${ }^{5}$ Filme “A maçã” (1998). Irã. Direção: Samira Makhmalbaf. Sinopse: Zahra e Massoumeh são as personagens reais. Parecem retardadas porque passaram enjauladas em casa onze dos seus treze anos de vida. Seus pais simples e idosos, com a agravante da mãe ser cega, pensavam estar seguindo alguns vagos preceitos do Alcorão...uma que diria que meninas são como flores e que expostas ao sol murchariam.

${ }^{6}$ Nome fictício. Agradecemos a ela por ceder o registro.

${ }^{7}$ Estas impressões são fruto de um exercício de escrita a partir da leitura do filme “A maçã”, no contexto de uma disciplina da Pós-Graduação em Educação em 2000.
} 
não podiam pular, não sabiam FALAR (e lembro que numa aula se fala de DAR A PALAVRA e dizer que os alunos não falam na sala porque não tem a oportunidade $e$ não porque eles não possam). Essas meninas que não tinham interação com sua mãe, com o seu pai com ninguém. Elas fora do mundo, longe do social e do intercâmbio e da interação... Seu mundo fechado, escuro, um mundo que não oferece estímulos para elas. Sem modelos, sem espelhos onde olhar-se. Com uma mãe temerosa. E um pai que pensa em: ensinar a fazer arroz para se casar. E voltaram minhas lembranças... E minha mãe contando sempre para mim que ela não pode continuar estudando e fazer $o$ colegial porque seu pai e um irmão dela falavam que só tinham homens na escola e não era certo que ela fosse a única mulher. Então outra porta que se fechou.

A porta se abre. O espelho, o pente, o caminhar pelas ruas sozinhas, o sorvete e a necessidade de dinheiro para poder comprar. E a aparição da maçã pendurada e a vontade de comer maçã. E a maçã como elemento que vai começar a ligar as meninas com os outros. $O$ caminho até a frutaria e outra vez a necessidade do dinheiro para comprar. E chegou para mim o momento de mais riqueza, o aprender com o outro. Brincar de amarelinha, de trepador... As meninas no parque ensinando como pular, com quais pernas, mostrando, guiando, e lembrei de Vigotski e de sua ZDP e do papel das mães como facilitadoras. E o papel destas meninas ensinando. Os primeiros contatos afetivos, batendo e depois beijando.

E o que achei muito interessante foi ver como as filhas foram levando aos seus pais até o social. Ao pai pela necessidade de comprar o relógio e à mãe, que não quis ficar sozinha na casa e preferiu abrir a porta da sua casa e sair em busca deles. Foi surpreendente ver à mãe caminhar sozinha pela rua e achar a maçã pendurada.

Qual foi o sentido da escolha da maça como instrumento facilitador? Será que tem a ver com a maçã de Adão e Eva? Será que a maçã representa o que não é permitido? (Registro de Lana, 2000).

É a partir das “Minhas impressões”, o primeiro registro elaborado por Lana, que pretendemos desenvolver a continuação a importância e potencialidade da experiência estética, no caso, a de assistir um filme, na formação dos professores.

Ao considerar que no encontro do espectador com o filme, sempre acontece uma experiência estética ${ }^{8}$ desse sujeito, estamos explicitando que esse sujeito tem a vivência de acompanhar essa narrativa estética e ao fazê-lo o faz de forma estética. O encontro estético do sujeito com o objeto, no caso o filme, implica que o primeiro se abandona à obra o que significa: deixar-se emaranhar pela obra, deixar-se envolver por ela... Mas esta experiência estética só se torna uma leitura estética quando este mesmo sujeito que vivenciou a experiência estética retorna a si mesmo e se pergunta pelos sentidos do que acabou de lhe acontecer. A busca pelos próprios sentidos não é uma leitura "neutra” do filme, já que o sujeito não pode desconsiderar sua experiência. É nesse momento, de retornar a si mesmo,

\footnotetext{
${ }^{8}$ Agradecemos ao Prof. João Wanderley Geraldi que colaborou com as discussões referentes à experiência estética e suas possíveis leituras.
} 
que o sujeito se pergunta pelos sentidos e assim vai construindo compreensões, traduzindo sua experiência vivida ao narrável, ao descritível, ao compreensível. Assim, desde uma perspectiva bakhtiniana consideramos leitura estética aquela na qual o sujeito convidado a assistir ao filme toma seu referencial de vida, seu processo histórico, e a partir deles se vê mobilizado a produzir sentidos, os que surgiram a partir da relação estabelecida com essa experiência vivida.

E a trama é vivida e talvez até revivida, uma vez que suas histórias são mobilizadas, significadas e ressignificadas. Há um processo inicial de mobilização de sentidos, de emoções, de elaboração de compreensões construídas pelo sujeito. Como aponta Oliveira Jr. (1999. p. 171), quando assistimos a um filme nos envolvemos com o que foi visto na tela, criamos vínculos afetivos com um ou vários personagens, tornando minhas as suas angústias, dores e alegrias.

No uso cotidiano dos filmes em sala de aula nos cursos de formação, a primeira pergunta após a exibição é a seguinte: o que acharam do filme? Talvez seja também a primeira pergunta que realizamos ao nosso companheiro de idas às salas de cinema.

Mas fazer esta pergunta em sala de aula tem um caráter especial. Diferentes respostas são pontuadas. Respostas que se revelam com um simples “não compreendi nada”, com um "gostei muito", ou com silêncios, ou com uma ou várias lembranças sobre experiências vividas. E cada um proporciona um sentido para o que viu e viveu, pois materializa-se na obra de uma determinada forma, tornando-se sujeito dela. E na medida que se tornam sujeitos da trama, choram, se irritam, querem mudar o rumo dos personagens.

"Nos filmes as imagens se materializam diante de nós, dando uma densidade muito grande ao que estamos vendo/vivendo; tendemos a sentir os acontecimentos que vemos na tela como se estivéssemos no corpo daquele personagem mostrado pelas câmeras. O fato de as imagens se seguirem umas às outras ininterruptamente, fora do controle do espectador, impede que este realize um movimento reflexivo do tipo: “isto não é real”, o que reduziria, sem dúvida, a identificação da imagemcorpo com o corpo concreto (pele, carne, eletricidade, etc). bem como as sensações presenciadas/sentidas durante a projeção. Podemos dizer, então, que, antes de mais nada, ou seja, primeiramente, sentimos o filme como um todo, cada imagem nos chega como num susto. O entendimento de um filme tem um caráter afetivo próprio das situações globalizantes, orais” (OLIVEIRA JUNIOR, 1999, p. 168). 
Vejamos quanta materialidade foi construída a partir da experiência da aluna, repleta de emoção, de sua história, de suas dores e delícias, das reflexões e compreensões promovidas pela experiência estética.

Na intencionalidade do trabalho com a produção artística podemos racionalizar e proporcionar reflexão sobre as múltiplas sensações/emoções provocadas pelo filme. A produção pode proporcionar uma amplitude grande de discussão a partir de sua assistência.

A proposta inicial que culminou neste registro de impressões apresentado acima, era que os alunos assistissem ao filme coletivamente, mas passou a ser uma atividade individual quando de uma greve instaurada na Universidade. A professora que ministrava essa disciplina em nenhum momento deu indicações e/ou sugestões sobre o que olhar ou sobre o que e como olhar, ou sobre o que ou como relacionar o filme com o que nesse curso estava sendo desenvolvido. Também não solicitou que fosse realizada uma escrita a partir do mesmo. O que chama a atenção no registro apresentado é que, além das emoções surgidas, também um movimento de refletir e racionalizar estas emoções com questões relacionadas à disciplina. É neste ponto que gostaríamos de tratar da importância do que pretendemos denominar como leitura didática quando o sujeito que assiste ao filme tece diálogos com os autores e perspectivas teóricas tratadas na disciplina e que lhe permitem ampliar as compreensões relativas às questões específicas da mesma.

Importa considerar que a vivência estética está influenciada pelo contexto em que ela se dá. Nesse sentido, experienciar uma obra no contexto escolar pode produzir sentidos ou orientações de sentido que a mesma obra, vista em outro ambiente, não teria. Assim, quando essa experiência estética acontece na escola, ela está atravessada por um objetivo didático e isso porque após assistir o filme sempre há uma discussão sobre o mesmo e portanto, mais do que uma construção de compreensão, há uma racionalização desta compreensão, desta vivência estética. Esta seria uma das formas de ler um filme, a leitura didática porque atrelada a algum objetivo. A seguir apresentamos alguns trechos do trabalho final da mesma aluna que escolheu tratar dos estudos desenvolvidos na disciplina a partir do filme referenciado. 
Trabalho final

O SOCIAL -INTERAÇÃO - ZDP

Enquanto assistia ao filme chegaram muitas imagens. Mas enquanto as meninas brincavam no parque a relação com Vigotski foi imediata. A relação primeira foi a ZDP. Eu conheci a teoria de Vigotski no meu último ano da faculdade, estudando Didática do Ensino Infantil. Nesse momento eu fiquei surpresa pelas suas afirmações, o exemplo da mãe que vai ensinando a seu filho, tentando ir sempre mais além da suas possibilidades, como você fala [a professora da disciplina] esticando ao máximo o que pode-se fazer.

Vigotski chama de zona de desenvolvimento proximal à distância entre o nível de desenvolvimento real, que se costuma determinar através da solução independente de problemas, e o nível de desenvolvimento potencial, determinado através da solução de problemas sob a orientação de um adulto ou em colaboração com companheiros mais capazes (1999, pág. 97).

A brincadeira da amarelinha, as meninas que mostram como fazer, ensinando que é pular, ensinando como pular, com que pé, em que lugar, como jogar a pedra, dá conta de essa ZDP e das possibilidades certas de ter um desenvolvimento. Estes primeiros contatos sociais, essas interações, dão conta da teoria de Vigotski. Tem um outro que me ensina, que me guia, que me ajuda, que me mostra. É na relação com outras pessoas que entramos em contato com o mundo. Viver e estar com o outro é a condição para nosso desenvolvimento. Por isso a importância do aspeto social. O contato corporal com um outro também foi um aprendizado. Os contatos afetivos, as gêmeas não sabiam dar beijos, elas só batiam como mostra de afeto.

Pontuar o conhecimento necessário a formação de professores a partir do filme pode nos indiciar que ele possibilitou a aluna a ampliação do conhecimento sobre a psicologia do desenvolvimento infantil, essencial a formação pessoal e profissional. Neste sentido a atividade constituiu-se em uma leitura didática, uma vez que aproximou-se dos conhecimentos didáticos essenciais a formação, previstos na disciplina em questão.

Em outra passagem do mesmo registro, um novo conhecimento didático, que fazia parte do repertório da disciplina, foi passível de leitura pela aluna.

\section{O PODER DA PALAVRA -FALAR-DAR A PALAVRA}

As meninas do filme não falam. O que é a fala, a linguagem? A linguagem é uma atividade simbólica que nos caracteriza como espécie. Essa atividade simbólica inclui os jogos, os gestos, os desenhos, a palavra. [...]

Na sala continuamos falando sobre a palavra. Assim apareceu a palavra como a mais importante de todos os signos. Segundo a fala do Bakhtin:

"tudo que é ideológico possui um significado e remete a algo situado fora de si mesmo. Em outras palavras, tudo o que é ideológico é um signo. Sem signos não existe ideologia" (1999, p. 31).

"Tudo o que é ideológico possui um valor semiótico" (1999, pág.32).

"A palavra é o fenômeno ideológico por excelência. A palavra é o modo mais puro e sensível da relação social” (1999, p. 36). 
Continuando com os conceitos de palavra e ideologia, fomos vendo como é que a ideologia vai se formando. Olhamos que a consciência do homem se forma na consciência do outro, aprendemos o mundo pelo outro, em relação com o outro, pela palavra do outro. Assim concluímos que a palavra do outro é constitutiva da própria identidade. Em relação com o filme a falta de palavras das meninas não permitiu a constituição dessa identidade.

Bakhtin fala dessa constituição de identidade através de duas formas bem definidas. Por um lado através das situações cotidianas, desde uma perspectiva dialógica isto implica que o discurso vem de outro e remite ao outro que responde, comenta e esse processo modifica as falas dos que participam desse discurso. Por outro lado ele fala de processo de formação ideológica que vão se dar através de situações deliberadas, que se caracterizam por ter uma intencionalidade. Este processo tem a ver com a nossa relação com a palavra do outro. Desde este lugar vão a aparecer dois caminhos e se pode falar de palavra autoritária e palavra persuasiva interior. A palavra autoritária é reconhecer a palavra do outro como uma palavra de autoridade, é permitir que o discurso do outro entre no meu discurso investida de autoridade, a ponto de reproduzir tal qual é dita pelo outro. Implica reconhecer ao outro como alguém que tem um lugar de autoridade frente ao conhecimento. A palavra persuasiva fala da possibilidade de convencer ao outro, a palavra dita vai se entrelaçando com as nossas palavras, a relação com esta palavra não é de autoridade mas vai deixando marcas no nosso discurso.

O fato das meninas não falarem, ao menos a partir do signo da palavra, é disparador de uma discussão sobre o conceito de fala em Bakhtin. A autora, envolvida pelo conteúdo didático da disciplina, mobilizada pelos sentimentos que o filme lhe causa e na espera de responder ao que supostamente ela acredita que a disciplina requer, aproxima conceitos de Vigotski e Bakhtin em seu trabalho final.

Mas, a partir do registro apresentado também foi possível perceber outras relações estabelecidas com ele. A aluna considerou a maçã utilizada no filme como elemento facilitador para o ingresso tanto das meninas como de sua família na cultura e ainda questionou se a maçã representava a punição e o proibido ao fazer referência a Adão e Eva. E ao apontar estas questões no trabalho final, a aluna teceu relações com a literatura ao fazer referência ao livro de Isabel Allende:

$M A C ̧ \tilde{A}$

No percurso da disciplina, retomei a leitura de um livro que tinha me sido presenteado pelo meu marido há dois anos. O livro é "Afrodita” de Isabel Allende.

Quando eu escrevi o que você [a professora da disciplina] chamou de "metáfora", em relação à maçã, eu não tinha acabado de ler o livro ainda.

Nas "Minhas Impressões" eu me perguntei o por que do uso da maçã como elemento facilitador? Porque foi na procura dela que as gêmeas começam o contato com o mundo.

Perguntei-me também: será que representa o que não é permitido? Não era permitido 
sair, ter contatos. $O$ que elas na realidade não tinham permitido fazer era interagir com os outros e a partir de querer pegar a maçã é que se desenvolvem os intercâmbios.

Surpresa fiquei quando li o que Isabel Allende achou em relação à maçã. Isabel Allende (1997) escreve no seu livro "Afrodita":

“Maçã é o símbolo da tentação.

E Jeová Deus ordenou ao homem dizendo: De toda arvore do horto poderás comer; mas da árvore da ciência do bem e do mal não comerás, porque no dia em que delas comeres, certamente morrerás. - Gênese 2:16-17

Mas a serpente convenceu a mulher e esta ao seu companheiro e ambos comeram e aí começaram os problemas do casal humano. No entanto, a Bíblia não diz que o fruto era uma maçã. Supõe-se que os padres da Igreja -celibatários e misóginos -tenham escolhido a maçã como fruto proibido porque, quando cortada pela metade, aparecem as sementes dispostas em forma de vulva, parte da anatomia que a malvada Eva usou para tentar o bom Adão. Mais adiante na história, Sulamota canta para Salomão:

Sustentai-me com passas, confortai-me com maçãs, porque estou doente de amor. Cantares 2:5

De qualquer forma, a fama da maçã nas lides do amor é universal. Era usada em muitas poções mágicas, filtros e encantamentos. Os licores de maçã como o calvados $e$ a sidra, são estimulantes e acredita-se que rejuvenesça” ( $p .161)$.

Este registro, deixou em evidência que as diferentes formas de ler um filme se entrecruzam. Neste caso, ao pensar na maçã como elemento facilitador, mediador no ingresso das personagens na cultura, a aluna explicitou a sua leitura didática e posteriormente a partir dela fez uma leitura estética: o sujeito envolvido com a trama procurou novos sentidos e compreensões que não fossem na linha da racionalização.

A partir da experiência estética que neste trabalho foi apresentada, acreditamos que considerar o filme no contexto da sala de aula é um elemento provocador para todo aquele que o assiste quando, como já assinalado, ele promove e potencializa diferentes formas de ler, sendo que tanto a leitura estética como a leitura didática, possibilitam o tecido de redes de sentidos, sensações, compreensões, reflexões, e que juntos permitem ampliar a leitura e interpretação acerca de uma temática.

Para onde não poderíamos encaminhar a discussão disparada pela escrita? Não queremos dizer que todo o trabalho com a leitura de imagens deve ser realizado a partir da escrita e da leitura da imagem. Este registro pode ser feito por diferentes produções como literárias, imagéticas, inclusive com a possibilidade do diálogo com os alunos após a obra ter sido apresentada. 
O que nos importa aqui é pensar que no uso na formação dos professores, o filme pode provocar além de reflexões sobre o conteúdo, reflexões a partir de nossa identificação ou não com o filme que é uma obra de arte, antes de ser um filme utilizado em sala de aula.

\section{INTENCIONALIDADE E PRODUÇÃO DE SENTIDOS}

Dos sentimentos advindos ao assistir um filme e de seu movimento de racionalização que passa ou não pela intenção que o professor tem em discutir determinados temas a partir dela, há uma consideração que não pode ser excluída deste tema, referente à forma de escolha do filme pelo professor e como o seu conteúdo é ou não veiculado como verdade.

Freqüentemente, em razão de um movimento de repúdio à simplificação do conhecimento em sala de aula, tendemos a questionar certas práticas denominadas tecnicista e tradicionais, que enfatizam os meios ou então eliminam o sujeito da aprendizagem. Acreditamos que, se partimos da complexidade do trabalho escolar, proporcionar práticas que caem nestas perspectivas pode oferecer uma suposta simplificação do conhecimento que está no mundo. Tendemos a temer que esta prática nos leve a fechar fronteiras do incerto, a fechar questionamentos.

No entanto mesmo com esta tentativa de induzir a leitura, de restringir a obra, ela continua sendo arte e como tal produz, independente da vontade de quem a exibe num momento escolar, sentidos múltiplos em quem a assiste. Isto se deve especialmente pelo fato de que as imagens das produções culturais não obedecem a objetivos pedagógicos, didáticos e seriações artificiais (MIRANDA, 1998). Este tipo de objetivo é delegado às produções destinadas à educação escolar, que geralmente são mais pobres, pois reproduzem uma artificialidade do real.

Ao fazer a escolha de um ou outro filme, já não temos uma intencionalidade prévia?

E aqui vale pensar a questão da intencionalidade na escolha da obra. Oliveira Jr. (1999) questiona as formas utilizadas pelos professores na apresentação dos filmes, que difere 
totalmente do modo em como eles são produzidos: "não é facilidade que um filme busca, mas entendimento, ampliação do conhecimento” (p. 169).

Na mesma linha Almeida (1999) questiona que a forma como os filmes são analisados e/ou explicados na sala de aula, seguem os mesmos passos que são aplicados aos textos, dentre eles o autor aponta, "fidelidade às fontes e aos fatos”, a "busca de leis gerais e universais”, a “unicidade ideológica”, perceber o filme como “uma visão de mudo homogêneo", a "atribuição de intencionalidade ou simbolismo”, etc. Ainda segundo ele, isso, leva a fazer uma leitura das "imagens e dos sons em movimento, sua morfologia, sintaxe e semântica peculiares" como se fosse um documento escrito, e assim buscando seu entendimento (p. 162).

A partir do questionamento de Almeida (1999) sobre a intencionalidade, nós nos perguntamos se essa intencionalidade não ocorreria a partir do momento em que como professoras, ao planejar o trabalho na sala de aula, fazemos uma relação entre a obra (filme/pintura/poesia) e o conhecimento a ser tratado em determinado curso, independente dos passos apontados pelo autor acima. A intencionalidade ocorre a partir do momento em que há identificação entre a obra e o conhecimento primeiro a ser tratado em um determinado curso.

Mas o que a obra proporciona é uma ampliação deste conhecimento, um ir além, porque possibilita a articulação entre a sua história de vida, seus sentimentos, suas lembranças, o que está sendo objeto de estudo e todas as outras possibilidades deste objeto: a leitura didática e estética. E, a medida que acontece este encontro, o conhecimento é problematizado, e complexificado.

Assim, muitas vezes a escolha por um filme tem a ver mais com o fato do professor, ao vê-lo, considerar que a partir dele, pode estabelecer em aula, com os seus alunos, uma discussão, aprofundamento e complexificação de um determinado conhecimento, do que necessariamente construir um olhar. Importa lembrar que qualquer que seja a perspectiva do professor acerca da educação, ao escolher um filme ele sempre o faz com certa intencionalidade pois esta é inevitável na escolha de um filme. Mas acreditamos que a intencionalidade de um filme, a partir de uma perspectiva metodológica tecnicista ou tradicional, ganha outros sentidos porque aparece um novo componente: uma forma de controle da obra a partir dos conhecimentos que se pretendem trabalhar, tornando o caráter do 
filme como auxiliar e conseqüentemente como recurso, instrumento e não como eixo do conteúdo do programa

No entanto, a obra em si, mesmo que escolhida em um determinado contexto de ensino, mesmo que apresentada com um determinado roteiro de estudo, enquanto produção artística, proporciona mais que uma leitura pelo sujeito. Na ação pedagógica, o professor não controla os sentidos do sujeito diante de uma produção da cultura ${ }^{9}$.

Como aponta Geraldi (2003), desde uma perspectiva bakhtiniana, é impossível prever quais as contrapalavras que serão produzidas no encontro do sujeito com a obra, "porque elas comparecem segundo os percursos já percorridos por cada diferente leitor e segundo os inumeráveis momentos da leitura, é impossível prever todos os sentidos que a leitura produz” (p. 259). Nesse sentido, o mesmo autor considera que uma vez criado o texto, ele mesmo passa a ter histórias “que não são a reprodução de sentidos sempre idênticos a si mesmos” (p. 9).

E esta diversidade pode ser problematizada quando da escolha de filmes para trabalhar em sala de aula. E é interessante pensarmos sobre as formas com que escolhemos os filmes que serão "transmitidos" aos nossos alunos. Temos um determinado curso a ser oferecido, determinados temas a serem desenvolvidos e aí, pensamos em formas alternativas de trabalhá-lo. Então lembramo-nos das outras linguagens porque acreditamos na complexidade do fenômeno educativo. Até que ponto rompemos com uma perspectiva tradicional, instrumental de ensino? Ou seria apenas uma questão de intencionalidade?

Talvez este rompimento está na medida que há a liberdade de complexificar o conhecimento pelas leituras possíveis que o filme provoca, uma vez que sua linguagem narrativa - não carrega simplismos, mas dilemas, conflitos, contradições, que podem, no trabalho pedagógico, “convergir para um percurso"10 da aula, a partir das possíveis leituras que foram provocadas.

\footnotetext{
${ }^{9}$ Poderíamos elencar vários estudos que tomam a produção cultural como resultado de múltiplos significados estabelecidos pelos sujeitos. Os estudos de Hall (2001), Bhabha (1998) para citar alguns autores do póscolonialismo. E ainda nos estudos da obra de Bakhtin (1999).

${ }^{10}$ Segundo Oliveira Jr. (em conversa informal), “convergir para um percurso”, implicaria estar disponível para conversas futuras, podendo os alunos consultar cartazes, portfólios, blogs, etc., com o objetivo de que o diálogo instaurado a partir do filme, tenha continuidade e não se perca.
} 
Cremos que ainda há uma questão a ser pensada a partir das pontuações acima, a forma como a obra entra como ilustração, como recurso didático e não como objeto cultural na sala de aula. Ao torná-la recurso perde-se sua dimensão de objeto cultural (MIRANDA, 1998).

Neste sentido, acabamos por descartar a linguagem artística porque não é científica e a tornamos mera ilustração e não produção. Oliveira Jr. (1999) também nos alerta sobre a forma em que enxergamos as imagens do cinema, quando em uma atividade na sala de aula, na escola:

\footnotetext{
"Lembro que as imagens do cinema nos chegam sempre como verdadeiras, materiais. Ao colocarmos na escola as imagens desse filme estaremos reforçando este caráter de verdade, só que desta vez com a chancela do conhecimento cientifico escolar "(OLIVEIRA JUNIOR, 1999, p. 173).
}

A possibilidade do uso do filme em sala de aula ultrapassa a perspectiva dos materiais que demonstram uma visão restrita ou estagnada/fixa do mundo, ou ainda como mera ilustração, deixando de lado duas possíveis dimensões da obra: a possibilidade do conhecimento sobre o momento histórico retratado, por exemplo; e a ficção, fantasia do roteiro. Qual a razão? As histórias contadas na produção cinematográfica são narrativas de múltiplos significados e de muitas possíveis fantasias.

Ao promover a discussão dos sentidos produzidos pela obra, estamos mobilizando diversos sentidos do sujeito que a assiste, sem controle (BAKHTIN, 1999). Se assim o é na relação entre professor e aluno em sala de aula, muito mais numa produção que traz a multiplicidade e a complexidade dos fenômenos sociais ou outros, como se caracteriza a produção da cultura. Nesse sentido, Kramer (1997) considera como Bakhtin, que “toda leitura envolve três participantes: a leitura é sempre resultado de uma parceria ativa entre o autor, o leitor e a obra” (p. 23). E esta parceria não é passível de diálogo linear, há elementos que não são controlados, mas que aparecem a partir dos referencias individuais, históricos, de cada sujeito envolvido.

Ao pensarmos nestes participantes acima, é inevitável não pensar a que contexto da obra nos referimos. Aqui merece um destaque especial o contexto em que cada obra é construída e nesse sentido apontamos que diferentes contextos, diferentes técnicas de produção, diferentes ideologias do mercado cinematográfico, diferentes visões de mundo dos 
Área Temática: Educação, Comunicação \& Tecnologia

diretores, proporcionam diferentes sentidos na sua leitura. Como considera Miranda (1998) "ao vermos o cinema como objeto cultural, o consideramos como uma visão de mundo de diferentes diretores e que tem uma linguagem que performa uma linguagem verbal” (p.16).

Lembremos do filme “A maçã” e questionemos se um roteirista e diretor que teve seu trajeto histórico em outra cultura, que não a iraniana, teria o mesmo potencial para produzir esta obra. Possivelmente não. Os elementos do contexto que cada sujeito carrega consigo podem marcar profundamente suas posturas, sua visão de mundo e, conseqüentemente, a forma de ler determinados fenômenos, especialmente o educacional.

A autora do referido filme, diretora da obra, é iraniana, e só ela, pode nos dizer de sua obra daquela determinada forma, pois vive seu lugar. O leitor, a Lana, a partir de sua experiência de vida, ressignifica a obra, que é um retrato de um determinado lugar a partir de um determinado sujeito, a partir do seu lugar, a partir de sua história, a partir dos fios que foram sendo tecidos na sua vida. Isto se configura numa polissemia por parte de todos os que se envolvem na obra. Isto não significa que, não há intencionalidade por parte de quem escreve a obra e logicamente, por parte do contexto em que este sujeito se insere. Podemos pensar que para além do contexto no qual o filme foi produzido, ainda que o filme tenha sido produzido em culturas diferentes das próprias, eles ecoam em nós, sujeitos espectadores.

\section{ALGUNS APONTAMENTOS}

Diante de nossas reflexões não queremos polarizar se é necessário ou não utilizar o filme em sala de aula, apenas apontar algumas considerações sobre o seu uso nesse espaço.

Considerações que passam necessariamente pela compreensão do que é um filme, do que é uma produção artística, e do que é uma prática pedagógica que promova a multiplicidade de sentidos e de leituras. Assim, pensamos na necessidade de refletir sobre qual o nosso lugar como professoras de futuros professores ao acreditarmos na importância de promover nesse processo de formação a possibilidade de vivenciar/experienciar outras linguagens para além das técnicas de ensino já instituídas. Nesse sentido, concordamos com Oliveira Jr. (1999) quando nos alerta a respeito de que estejamos perdendo a oportunidade de “tornar a escola um lugar real de aprendizado para este mundo que está aí” quando optamos/escolhemos tratar os filmes como "textos a serem lidos e compreendidos parte por 
parte", quando uma outra possibilidade seria tratar de compreendê-los como "textos a serem vistos e sentidos como um todo". A partir disso, podemos considerar que o filme aparece como um outro, que no diálogo que com ele iniciamos, nos vá constituindo.

Em nossa experiência como docentes, passamos a perceber a partir do uso da produção que os nossos alunos têm mais a dizer do filme do que aquilo que havia pretensão de ser trabalhado. Percebemos que muitos daqueles que geralmente não participam dos diálogos que acontecem na sala de aula, a partir do filme, passam a conseguir e ter algo para se expressar.

A obra tem uma intenção lida tanto por cada um dos espectadores, como dos possíveis leitores, incluindo a nós professores. O que queremos afirmar é que no uso da obra (filme) com nossos alunos, suas respostas a partir dos filmes apresentados, deixaram em evidência uma afirmação de Oliveira Junior (1999): “O importante é lembrar que para um filme caber na escola é preciso nos prepararmos para que ele extrapole os muros dela, para conversarmos sobre aquilo que ele diz a mais do que o que estava no programa” (p. 174).

É nesse sentido que temos apresentado aqui a experiência de uma aluna que a partir de sua vivência com o filme foi provocada a registrar suas várias compreensões, mostrando que é possível extrapolar os muros, estabelecendo diálogos para além dos conteúdos da disciplina.

Extrapolar os muros da escola e proporcionar sentido(s) para os conhecimentos historicamente produzidos, é provocar o eterno questionamento sobre o mundo, e cabe a nós professores, provocar os processo de compreensão desta linguagem na escola, ao mesmo tempo utilizar-se dela como maneira de entender-se no mundo.

Finalizamos com a certeza de que, muito mais que respostas sobre a relação formação de professores e filmes, tenhamos nos encaminhado por um trajeto nada linear, mas repleto de lugarejos deliciosamente instigantes. 


\section{REFERÊNCIAS}

AlmeIDA, M. J. Cinema, Arte da Cidade. Pro-Posições, Campinas, v. 10, n.1 (28), p. 157162, mar. 1999.

ALVES, N. Contar o passado, analisar o presente e sonhar o futuro. In: ; OLIVEIRA,

I. B. Pesquisa no/do cotidiano das escolas: sobre redes de saberes. 2. ed. Rio de Janeiro: DP\&A, 2002.

BAKHTIN, M. Marxismo e filosofia da linguagem. São Paulo: Hucitec, 1999.

BHABHA, H. K. O local da cultura. Belo Horizonte: Editora da UFMG, 1998.

CANDAU, V. Didática em questão. Petrópolis: Vozes, 1985.

CERTEAU, M. A invenção do Cotidiano: artes de fazer. 8 ed. Petrópolis: Editora Vozes, 2002.

CHALUH, L. N. Leitura e escrita: possibilidades para a reflexão. In: PRADO, G. V. T.; SOLIGO. R. (Orgs.) Porque escrever é fazer história. Campinas: Graf. FE, 2005.

DAMASCENO, E. A. Saberes e Conhecimentos docentes e formação de professores: dos saberes e conhecimentos da prática aos saberes e conhecimentos da formação. 2005. Dissertação (Mestrado em Educação) - Faculdade de Educação, Universidade Estadual de Campinas, Campinas, 2005.

DICKEL, A. Que sentido há em se falar em professor-pesquisador no contexto atual? Contribuições para o debate. In: GERALDI, C. M. G.; FIORENTINI D.; PEREIRA, E. M. A, (Orgs.) Cartografias do trabalho docente: professora(a)-pesquisador(a), Campinas, SP: Mercado de Letras: Associação de Leitura de Brasil - ALB, 1998 (Coleção Leituras no Brasil).

FREITAS, Helena C. L. O trabalho como princípio articulador da Teoria e Prática: uma análise da Prática de Ensino e Estágios Supervisionados na Habilitação do Magistério do Curso de Pedagogia da FE/UNICAMP. 1993. Tese (Doutorado em Educação) - Programa de Pós Graduação em Educação, Faculdade de Educação, Universidade Estadual de Campinas, Campinas, 1993.

GARCIA, R. L.; ALVES N. Conversa sobe pesquisa. In: ESTEBAN, M. T.; ZACCUR, E. (Orgs.). Professora-pesquisadora - uma práxis em construção. Rio de Janerio: DP\&A, 2002.

GERALDI, Corinta Maria Grisolia. A produção do ensino e pesquisa na graduação: estudo sobre o trabalho docente no curso de Pedagogia-FE/UNICAMP. 1993. Tese (Doutorado em Educação) - Faculdade de Educação, Universidade Estadual de Campinas, Campinas.

GERALDI, J. W. A aula como acontecimento. Aveiro: Universidade de Aveiro Campus Universitário de Santiago, 2004. 
. Depois do 'show', como encontrar encantamento? Cadernos de Estudos

Lingüísticos, Campinas, v. 44, n. 44, p. 251-261, 2003.

GIMENO SACRISTÁN, J. Docencia y Cultura Escolar: Reformas y Modelo Educativo. Buenos Aires: Lugar Editorial, 1997.

HALL, S. A identidade cultural na pós-modernidade. 6. ed. Rio de Janeiro: DP\&A, 2001.

HARGREAVES, A. Dimensiones subjetivas y institucionales de la formación docente. In: BIRGIN, A. et al. (Orgs.). La Formación Docente: cultura, escuela e política. Debates y experiencias. Buenos Aires: Troquel Educación, 1998. p. 135-146.

KRAMER, S. Por entre as pedras: arma e sonho na escola. 3. ed. São Paulo: Editora Ática, 2003.

Propostas pedagógicas ou curriculares: subsídios para uma leitura crítica. Educação \& Sociedade, ano XVIII, n. 60, p. 15-35. dez. 1997.

MIRANDA, C. E. A. Ver filmes, dizer educação, olhar cultura. Revista de Educação PUCCampinas, v. 3, n.5, p. 13-20, 1998.

NAPOLITANO, M. Como usar o cinema na sala de aula. São Paulo: Editora Contexto, 2003.

OLIVEIRA JR., W. M. Filmes \& Professores: Momentos de uma oralidade muito presente. Pro-Posições, v. 10, n.1(28) março de 1999. p.163-178

ROCKWELL, E.; EZPELETA, J. Etnografia na pesquisa educacional. In: ;

(Orgs.). Pesquisa participante. São Paulo: Cortez: Autores Associados, 1986. p. 9-30.

TEIXEIRA, I. A. C.; LOPES, J. S. M. A escola vai no cinema. 2 ed. Belo Horizonte: Autêntica, 2003. 
ADRIANA VARANI

Pedagoga - professora dos anos iniciais do ensino fundamental. Doutora em Educação pela Faculdade de Educação da UNICAMP, pesquisadora do Grupo de Estudos e Pesquisas em Educação Continuada (GEPEC) e, atualmente professora da PUCCAMP. E-mail: adriana varani@yahoo.com.br

LAURA NOEMI CHALUH

Professora para o Ensino Primário (Ensino Fundamental I e II). Licenciada em Ciências da Educação. Doutora em Educação pela Faculdade de Educação da UNICAMP, pesquisadora do Grupo de Estudos e Pesquisas em Educação Continuada (GEPEC).

E-mail: chaluh@uol.com.br

Recebido em: 28/07/2008

Publicado em: 31/01/2009 